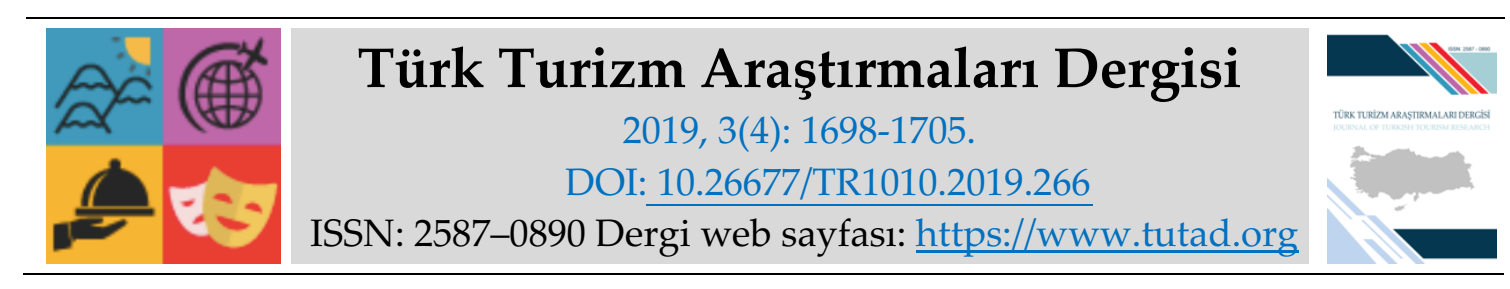

$\underline{\text { KAVRAMSAL MAKALE }}$

\title{
Konaklama İşletmelerinde Peyzaj Düzenlemelerinin Önemi
}

Doç. Dr. Yasin DÖNMEZ, Karabük Üniversitesi, Orman Fakültesi, Karabük, e-posta: yasindonmez@karabuk.edu.tr

ORCID: https://orcid.org/0000-0003-2840-6312

Doç. Dr. Fatih TÜRKMEN, Hoca Ahmet Yesevi Uluslararası Türk Kazak Üniversitesi, Sosyal Bilimler Fakültesi, Kazakistan, e-posta: fatihturkmen@karabuk.edu.tr

ORCID: https://orcid.org/0000-0001-6716-7399

Öz

Turizm işletmelerinde önemli bir yere sahip olan dış mekânlar, özellikle konaklama işletmeleri için önemli bir gerekliliktir. İnsanların dinlenme amaçlı gittikleri otel, tatil köyü gibi konaklama işletmelerinde, zamanlarının büyük bir bölümünü, açık havada geçirme arzusu, dış mekânları bu işletmeler için önemli bir hale getirir. Su sporları, çocuk oyun alanları, spor alanları ve diğer düzenlemeler turistlerin satın alma davranışları üzerlerinde etkili olan dış mekânlardır. Bu çalışmada literatür değerlendirmesi kapsamında, konaklama işletmelerinde uygulanan Peyzaj Düzenlemelerinin önemi vurgulanmaya çalışılmıştır. Ayrıca oluşturulan SWOT analizi tablosu ile konaklama işletmelerinde peyzaj düzenlemelerine önem veren işletmeler ile vermeyen işletmeler arasında bir değerlendirme de yapılmıştır. Sonuç olarak düzenli olarak dış mekân tasarımlarını yenileyen, turistlerin isteklerine göre oluşturulan alanlara sahip işletmelerin daha çok tercih edildikleri belirlenmiştir.

Anahtar Kelimeler: Konaklama İşletmeleri, Peyzaj, Peyzaj Düzenlemeleri.

Makale Gönderme Tarihi: 14.07.2019

Makale Kabul Tarihi: 06.10.2019

\section{Önerilen Atıf:}

Dönmez, Y. ve Türkmen, F. (2019). Konaklama İşletmelerinde Peyzaj Düzenlemelerinin Önemi, Türk Turizm Araştırmaları Dergisi, 3(4): 1698-1705.

(C) 2019 Türk Turizm Araştırmaları Dergisi. 


\title{
Journal of Turkish Tourism Research 2019, 3(4): 1698-1705. \\ DOI: $10.26677 /$ TR1010.2019.266 \\ ISSN: 2587-0890 Journal Homepage: https://www.tutad.org
}

\section{CONCEPTUAL PAPER}

\section{Importance of Landscape Arrangements in Hospitality Business}

Associate Prof. Dr. Yasin DÖNMEZ, Karabük University, Faculty of Forestry, Karabük, e-mail: yasindonmez@karabuk.edu.tr

ORCID: https://orcid.org/0000-0003-2840-6312

Associate Prof. Dr. Fatih TÜRKMEN, Akhmet Yassawi University, Faculty of Social Sciences, Kazakhistan, e-mail: fatihturkmen@karabuk.edu.tr

ORCID: https://orcid.org/0000-0001-6716-7399

\begin{abstract}
Outdoor spaces, which have an important place in tourism enterprises, are an important requirement especially for accommodation companies. The desire for people to spend most of their time outdoors makes them important for these establishments. Water sports, children's playgrounds, sports fields and other arrangements are the outdoor spaces that influence the buying behavior of tourists. In this study, the importance of Landscape Arrangements in accommodation establishments is emphasized within the scope of literature review. In addition, with the SWOT analysis table, an assessment was made between the enterprises that give importance to landscape arrangements in accommodation establishments and those that do not. As a result, it is determined that the enterprises which regularly renew their outdoor designs and have areas created according to the wishes of tourists are preferred more it.
\end{abstract}

Keywords: Hospitality Business, Landscape, Landscape Arrangements.

Received: 14.07.2019

Accepted: 06.10.2019

\section{Suggested Citation:}

Dönmez, Y. and Türkmen, F. (2019). Importance of Landscape Arrangements in Hospitality Business, Journal of Turkish Tourism Research, 3(4): 1698-1705.

(C) 2019 Türk Turizm Araştırmaları Dergisi. 


\section{Gíriş}

Turizm, müşteri ile sürekli yakın iletişimi gerektiren sektörlerden biridir. Bu iletişimin güçlü olması müşteri memnuniyetini, sadakatini ve satın alma niyetini arttırmaktadır. Turizm sektörünün alt kollarından birisi olan konaklama işletmeleri de müşteri ile en yoğun şekilde iletişimin sağlandığı birimlerdir (Kendir vd., 2018). Ticari nitelikteki konaklama işletmelerinin temel amaçlarının başında yüksek doluluk oranıyla çalışarak arzu edilen kar hedefine ulaşmak gelmektedir. Bu hedef doğrultusunda müşteri memnuniyeti, yüksek ürün ve hizmet kalitesi, rekabet edebilir bir yapı, maliyetlerin minimum seviyeye indirilmesi gibi diğer amaçların da gerçekleşmesi gerekmektedir (Kaya, 2010).

Turizm gelirlerinin kaynağı, seyahat eden insanların bireysel harcamalarından oluşmaktadır. $\mathrm{Bu}$ nedenle pazarlama yöneticileri, bireylerin satın alma davranışlarını incelemek ve anlamak durumundadır. Turistlerin satın alma karar sürecinde etkilendikleri faktörleri tespit etmek, bu faktörleri iyi analiz etmek ile ürün ve hizmetleri bu yönde geliştirmek önemlidir. Örneğin, turizm faaliyetlerine katılan turistlerin hem bireysel hem de kitlesel olarak hareket ettikleri ve en fazla deniz-kum-güneş üçlüsünü tercih ettikleri görülmektedir. Turistlerin bu duruma benzer ihtiyaçları doğrultusunda ortaya çıkan talepleri, müşteri tatminini en üst düzeye taşıyacak ve müşteri tercihlerini ön plana çıkaran nitelikte bir turistik üretimi dikkate almak da ayrıca turizm pazarlaması açısından bir zorunluluktur (Morrison, 1989: 61; Hayta, 2008: 39; Correia ve Pimpao, 2008: 330; Emir ve Avan, 2010; Dönmez ve Türkmen, 2015; Kendir vd., 2019).

Tüketiciler satın alma tercihlerinde bulunmadan önce çeşitli kararlar vermekte ve bu kararlarından hareketle satın alma eyleminde bulunmaktadır. Genel olarak, tüketici karar alma sürecinin beş aşamadan oluştuğu kabul edilmektedir. Bunlar; sorunun belirlenmesi, bilgi arama, alternatiflerin değerlendirilmesi, satın alma kararı/tercihi ve aldıktan sonraki davranıştır (Solomon, 2001: 296; Dönmez ve Türkmen, 2015). Bu anlamda karar alma sürecinde turistler de belirtilen aşamalar çerçevesinde tatil tercihlerini belirlediklerinden konaklama işletmelerinin bu durumu dikkate almaları gerekmektedir.

Günümüzde rekabet her alanda olduğu gibi turizm sektöründe de yaşanmaktadır. Birey kendi için dünyadaki gelişmeleri yakinen takip etmektedir. İşletmelerde bireyleri isteklerine göre kendilerine hedef koymaktadırlar. Bu sebeple turizm gelirinden daha fazla pay almak isteyen turizm işletmeleri, farklı uygulamalar ve sundukları hizmetler ile turistlerin ilgilerini çekme gayretindedirler. Daha çok konaklama hizmeti veren işletmeler turistlerin satın alma davranıslarına göre, kendi bünyelerinde gerekli düzenlemeleri yapmaktadırlar. $\mathrm{Bu}$ düzenlemelerin başında da peyzaj düzenlemeleri gelmektedir (Yeşiltaş vd., 2011; Can vd., 2014).

Ülkelerin her yıl turizm sektörüne yönelik uygulamalarını teşvik etmesi ve bununla birlikte işletmelerin birbirleriyle olan rekabetleri sebebiyle her yıl farklı strateji geliştirme eğiliminde olmalarına yön vermektedir. Yönetsel açıdan da işletmeler verimliliği sağlamaya yönelik stratejilerin nasıl olması gerektiğini ortaya koymaktır. Dolayısıyla bu çalışmanın amacı konaklama işletmeleri için önemli bir yere sahip olan peyzaj düzenlemelerinin (dış mekân) önemini ortaya konulmasıdır.

$\mathrm{Bu}$ çalışmada kavramsal olarak arşiv/doküman taraması ve gözleme yöntemlerinden yararlanılmıştır. Peyzaj düzenlemelerine önem veren işletmeler ile vermeyen işletmeler arasındaki farkı koymak amacıyla bir SWOT analizi yapılmıştır. Böylece rekabet ortamının gün 
geçerek arttığı işletmelerin bu konuda turist isteklerine göre hareket etmelerinin önemi ortaya konulmaya çalışılmıştır.

\section{KONAKLAMA IŞLETMELERINNDE PEYZAJ TASARIMLARI}

Peyzaj düzenlemelerini turist ihtiyaçlarına göre uygun ve güzel biçimde yapmış bir işletme, turistler üzerinde olumlu etkiler oluşturmaktadır (Cooper vd., 1995). Böylece ziyaretçilerin tekrar tekrar aynı tesisleri kullanmaları söz konusu olabilmektedir. Ayrıca yapılan bu tür düzenlemelerin zamanın birçoğunu dışarıda geçirme isteği olan ve açı havada yapılan aktiviteleri seven turistlerin ruhsal ve bedensel yapıları üzerinde de olumlu etkiler oluşturduğu bilinmektedir (Şekil 1) (Cooper vd., 1995; Özgüner, 2004; Topay ve Küçük, 2010).

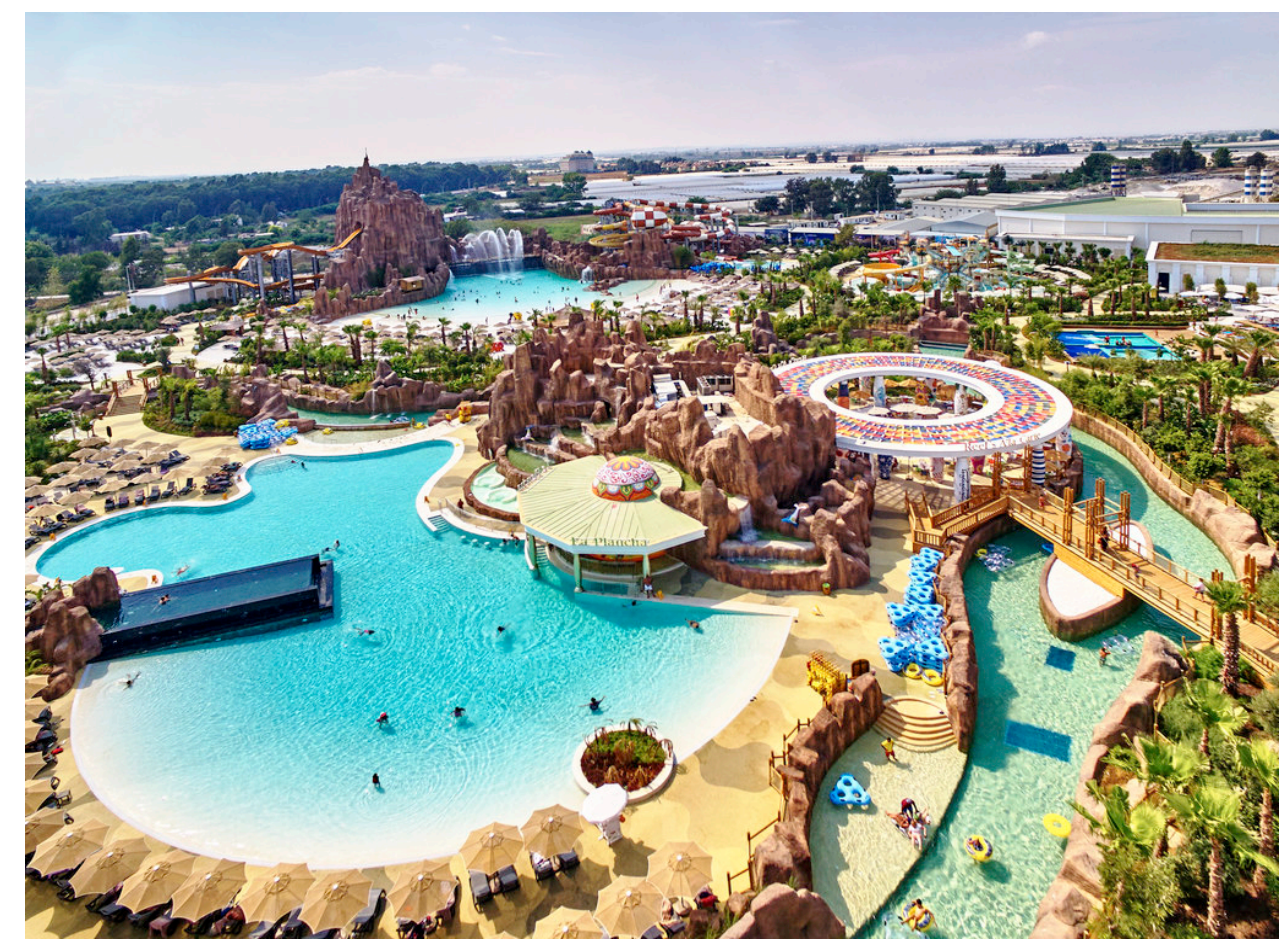

Şekil 1: Turistik Bir Otelde Peyzaj Tasarımı

Kaynak: (https://www.accorhotels.com.tr )

Yoğun bir iş dönemi sonunda tatil amaçlı olarak gittikleri tesislerin, kendilerine sundukları oda, servis ve yemek hizmetlerinin yanında dış mekânda sunulan hizmetler de turistlerin bu tesisleri seçme sebepleri arasında gelmektedir. Özellikle çocuklu aileler başta olmak üzere, konforu ve birçok aktiviteyi içerisinde barındıran turistik oteller öncelikli tercih sebebi olabilmektedir. Özgüner'e (2004) göre, Amerika Birleşik Devletleri'nde yapılan bir çalışmada, turistler için çekici bulunan yerlerin çoğunluğunun doğal alanlardan oluştuğunu, yeşil alanlara ve parklara yakın yerlerin daha değerli olduğu ve yeşil alanları olmayan yerlerdeki insanların yaşadıkları çevreden hoşlanmadıkları, kent doğal alanlarının insanlar için ne kadar önemli olduğu kanıt olarak gösterilmiştir. İlaveten parkların ve yeşil alanların insanlar için önemi daha çok rekreasyonel ve sosyal aktivitelerle ilişkilendirilmişse de insanların doğa ile görsel temele 
dayanan pasif ilişkilerden de önemli ölçüde psikolojik faydalar elde edebileceği de belirlenmiştir (Özgüner, 2004).

İnsanların farklı istek ve ihtiyaçları doğrultusunda turizm işletmeleri de farklı rekreasyon etkinliklerine ihtiyaç duymaktadır. Turizm ile peyzaj arasında ciddi bir ilişki bulunmaktadır. Dinlenme amacıyla gelinen işletmelerde zamanın büyük bir kısmını dış mekânlarda geçirme arzusu içinde olan turistlerin hem kendilerinin hem de aile bireylerinin ortak kullanacağ 1 alanlarının olması tesis için önemli bir avantaj içermektedir. Büyükler için tasarlanan yüzme havuzlarının yanında değişik derinliklerde veya formalarda tasarlanan havuzlar tesis seçiminde önemli bir etkendir (Cooper vd., 1995).

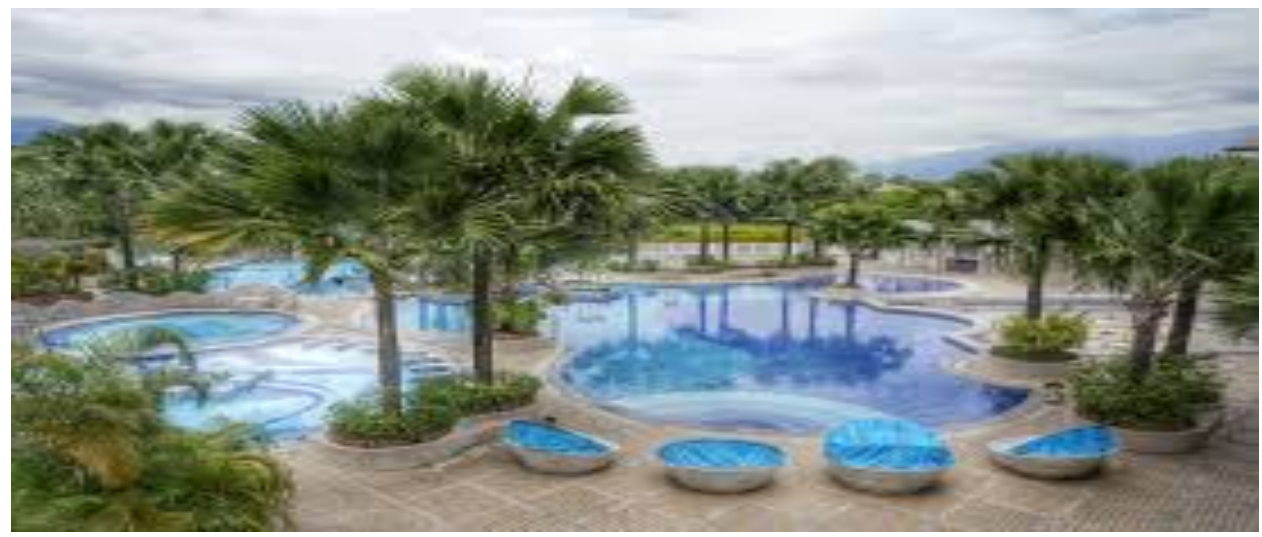

Şekil 2: Farklı Yaş Gurupları İçin Yüzme Havuzlarının Peyzaj Tasarımı

Kaynak: (https://pxhere.com.tr).

Konaklama işletmelerinde dinlenme amacıyla gelen bireylerin tatilleri esnasında dış mekanlarda gerçekleştirebilecekleri rekreasyon etkinlikleri Tablo 1'de verilmiştir. Buna göre turizm faaliyetlerine katılanlar için çok çeşitli ve farklı içerikte rekreasyon etkinlikleri bulunmaktadır. İşletmeler bu faaliyetleri göz önüne alarak yapacakları planlama işletmenin faydasina olacaktır.

Tablo 1: Rekreasyonel Turizm Etkinlikleri

\begin{tabular}{|l|l}
\hline - Güneşlenme & - Avcıllk \\
- Yürüyüş & - Off-road motosiklet sürme \\
- Yüzme & - Su alanlarını inceleme \\
- Futbol & - Hayvan besleme \\
- Tenis oynama & - Enstrüman çalma \\
- Golf oynama & - Paintball \\
- Her türlü oyunlar & - Ata binmek \\
- Basketbol & - Koşu yapmak \\
- Voleybol & - Aerobik \\
- Modern Danslar & - Hentbol \\
- Uçurtma uçurmak & - Bisiklet sürme \\
- Savunma sporları & \\
- Jimnastik &
\end{tabular}

Kaynak: (Giritlioğlu vd., 2017'den uyarlanmıştır). 
Tüm bu belirtilen hususlardan hareketle hane halkına göre daha fazla enerji tüketen konaklama tesislerinin kuruluş aşamasında kendileri için belirlenmiş standartların yanında yeşil yıldız kapsamında da girişimlerde bulunmalarıyla ve ilaveten çevre düzenlemesine yönelik çalışmalarla da alt yapı ve estetik açısından ağırlık vermeleri, turistlerin tesis seçiminde önemli bir faktör olarak değerlendirilebilir. Unutmamak gerekir ki turistler tesise ilk gediklerinde tesisin çevre düzenlemesinden ve ayrıca yeşil yıldız uygulamalarından etkilenebilmekte ve tesisle ilgili daha olumlu kanaatler geliştirebilmektedirler (Dönmez ve Türkmen, 2015).

$\mathrm{Bu}$ sebeple çalışma turizm terminolojisine turistlerin bakış açısından farklı bir boyut kazandırmakta olup, işletmecilere, tesis yöneticilerine turistlerin tesis seçiminde önemli fikirler sağlayabilecektir. Dolayısıyla turistik tesisler için müşteri kazanma yönünde yeni bakış açlarının oluşturulmasında, müşteriye özgü ürünlerin sunulmasında ve müşteri memnuniyetinin her anlamda yakalanmasında alışılagelmişin dışında orijinal farklılıkların yakalanması sağlanmış olabilecektir. Fache (2000) iş amaçlı seyahat eden müşterilerin otel seçiminde önemli gördükleri unsurları şu şekilde sıralamıştır: İleri teknoloji iletişim imkânları, güvenli yerde olması, sigarasız odaların varlığı, üstün güvenlik önlemleri, hızlı geri bildirim hizmeti, temizlik, sessizlik, havayoluna ulaşım imkânları, sıcaklık ve nem kontrolü ve çevre dostu odalar.

Tablo 2: Peyzaj Çalışmaları Uygulayan Konaklama İşletmelerinin SWOT Analizi

\begin{tabular}{|c|c|}
\hline Güçlü Yönler (S) & Zayıf Yönler (W) \\
\hline $\begin{array}{l}\checkmark \text { Müşteri memnuniyeti } \\
\checkmark \text { Müşteri çeşitliliği } \\
\checkmark \text { Çevre dostu işletme imajı } \\
\checkmark \text { Psikolojik beklentileri karşılayabilme } \\
\checkmark \text { Doğa manzarası } \\
\checkmark \text { Çocuklu aile beklentilerini karşılayabilme } \\
\checkmark \text { Huzurlu bir yerleşke } \\
\checkmark \text { Büyük işletme imajı } \\
\end{array}$ & $\begin{array}{ll}\checkmark & \text { Yüksek maliyet } \\
\checkmark & \text { Bürokratik engeller } \\
\checkmark & \text { Rekabet güçlüğ̈u } \\
\checkmark & \text { Yüksek fiyat uygulaması } \\
\checkmark & \text { İşletmenin geniş bir alana yayılması } \\
\checkmark & \text { Yüksek işçilik ve enerji giderleri } \\
\checkmark & \text { Daha fazla personel istihdam etme } \\
\checkmark & \text { Gençlere hitap etmemesi } \\
\end{array}$ \\
\hline Firsatlar (O) & Tehditler (T) \\
\hline $\begin{array}{ll}\checkmark & \text { Yeni trendlere uyum } \\
\checkmark & \text { Teşvik kolaylıkları } \\
\checkmark & \text { Kaliteli işletme görüntüsü } \\
\checkmark & \text { Uzman işgücü istihdamı } \\
\checkmark & \text { Çevreci örgütlerle işbirliği } \\
\checkmark & \text { Yeşil yıldız alma imkanı }\end{array}$ & 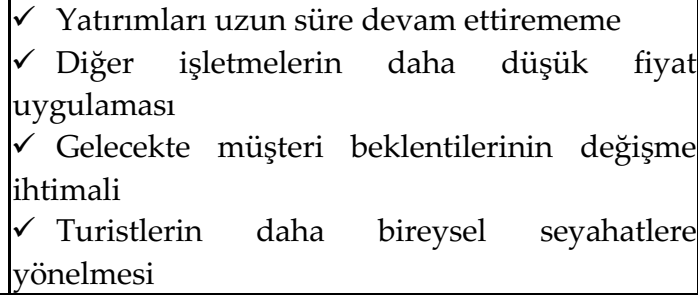 \\
\hline
\end{tabular}

Günümüz müşteri beklentilerinin hızla geliştiği ve çeşitlendiği bu dönemde turistlerin de işletmelerden beklentileri artmaktadır. Özellikle orta yaş ve üzeri çocuklu aileler konaklama yapacakları işletmelerde peyzaj alanlarına dikkat etmekle birlikte, konaklama süre ve bütçelerini de işletmelerin sunduğu kaliteye göre belirlemektedirler. Bu sebeple konaklama işletmelerinin hem müşteri beklentilerine uygun hizmetler sunması hem de müşterilerin kalış süreleri ve devamlılığını artırması bakımından peyzaj çalışmalarına önem vermeleri gerekmektedir. Bu hususta literatür taramasından yola çıkarak yapılan araştırma neticesinde konaklama işletmeleri için peyzaj çalışmalarının değerlendirilmesi Tablo 2'de SWOT analizi 
şeklinde sunulmuştur. Konaklama işletmelerinin belirlenen analiz dâhilinde kendi işletmelerinde olabilecek eksiklikleri tespit ederek hizmet sunacak olmaları yararlarına olabilecektir. Ancak unutmamak gerekir ki her konaklama işletmesi önce mevcut durumunu gözden geçirmeli, bunun yanında hedef müşteri kitlesini belirlemeli ve peyzaj çalışmalarını bu kapsamda şekillendirmelidir. Bu çalışmada sunulan SWOT analizi genel anlamda konaklama işletmelerine fayda sağlayabilecek hususlardan yola çıkarak genel bir değerlendirmeyi içermektedir. Elbette özelde konaklama işletmelerinin durumlarına göre de farklı unsurların ilgili tabloya eklenmesi söz konusu olabilir. Dolayısıyla konaklama işletmeleri genelde yapılan bu değerlendirmelerden hareketle özelde kendi durumlarını da düşünerek kendilerine göre bir uyarlama yapabilirler.

\section{SONUÇ VE ÖNERILER}

Ülkeler farklı alanlarda çeşitli teşvikler uygulayarak turizm gelirlerini artırmanın yollarını aramaktadır. Özellikle turizm sektöründe marka haline gelen turizm işletmeleri, turistlerin satın alma davranışlarına göre farklı düzenlemeler yapmaktadır. Yapılan her düzenleme işletmelerin tercih edilme düzeyini artırmaktadır. Sürekli olarak tek tip olarak yapılan düzenlemeler belli bir süre sonra turistlerin algisında düşmelere sebep olduğu için diş mekânlarda vakit geçiren turistlerin istek ve talepleri doğrultusunda peyzaj tasarım çalışmaları yapılması önemli bir uygulamadır.

Her ne kadar turizm faaliyetlerine katılanlar eğlenme, dinlenme, iyi vakit geçirme ve diğer isteklerini düşünerek tatil tercihlerine karar veriyor olsa da konaklama yaptıkları işletmelerin faaliyet alanlarının, eğlence birimlerinin ve çocuklar için organizasyonların sahip olduğu dış mekân ortamlarının büyüklüğünü de düşünmektedirler.

Sonuç olarak, dış mekânlarda gerçekleştirilecek peyzaj tasarım çalışmaları sektörde marka haline gelen turizm işletmeleri, turistlerin hedefleri ve beklentileri karşılaması yönündeki tercihlerini etkileyecektir. Bu şekilde, turizm işletmelerinin doluluk oranları arttırılabilir ve turistlerin kalış süreleri uzatılabilme imkânlarına sahip olunabilecektir

Konaklama işletmelerinin sahip oldukları mekânsal olanaklar göz önünde bulundurularak, turistlerin isteklerine bağlı olarakta değişen peyzaj düzenlemelerinin içerisinde yer alan havuz, spor alanları, çocuk oyun alanları, amfi tiyatroları, geniş çim alanları ile göze hoş gelecek olan bitkisel düzenlemeler işletmeler açısından önemli ayrıcalıkların arasında yer almaktadır.

\section{KAYNAKÇA}

Avan, A. (2010). Yabancı Turistlerin Satın Alma Karar Sürecinde Kültürel Varlıkların Etkisi: Konya Örneği, Selçuk Üniversitesi Sosyal Bilimler Enstitüsü Dergisi, (24), 203- 219.

Can, S., Türker, N., Öztürk, S., and Alaeddinoğlu, F. (2014). Tourists Perception of Green Practices in Eco Friendly Hotels a Case Study from the Antalya Region of Turkey. Journal of Tourism Challenges and Trends, 7(1), 9-27.

Cooper, C.P., Fletcher, J., Noble, A., and Westlake, J.N. (1995). Changing Tourism Demand in Central Europe: The Case of Romanian Tourist Spas. The Journal of Tourism Studies 6(2), 30-44.

Correia, A. and Pimpao, A. (2008). Decision-Making Processes of Portuguese Tourist Travelling to South America and Africa. International Journal of Culture, Tourism and Hospitality Research, 2(4), 330-373. 
Fache, W., (2000), Methodologies for Innovation and Improvement of Services in Tourism, Managing Service Quality, 10(6), 356-366

Dönmez, Y. ve Türkmen, F. (2015). Turistlerin Satın Alma Kararında Peyzaj Düzenlemelerinin Rolü: Belek Örneği. Turizm Akademik Dergisi, 2(2).

Giritlioğlu, İ., Olcay, A., Gündoğan, H. ve Alkan, B. (2017). Belek, Side ve Alanya Bölgelerinde Faaliyet Gösteren Otel İşletmelerinin Müşterilerine Sunduğu Rekreasyon Etkinliklerinin İçerik Analizine Yönelik Bir Araştırma, Mehmet Akif Ersoy Üniversitesi Sosyal Bilimler Enstitüsü Dergisi, 9(22), 235-250.

Hayta, A. B. (2008). Turizm Pazarlamasında Tüketici Satın Alma Süreci ve Karşılaşılan Sorunlar. Kastamonu Ĕ̆itim Dergisi, 16 (1), 31-48.

https://www.accorhotels.com/tr/hotel-B1J9-the-land-of-legends-kingdom/index.shtml Erişim Tarihi:10/09/2019

https://pxhere.com/tr/photo/798236 Erişim Tarihi:11/09/2019

Kaya, İ. (2010). Konaklama işletmeciliğinde stratejik yönetim süreci: Kavramsal bir yaklaşım. Karamanoğlu Mehmetbey Üniversitesi Sosyal ve Ekonomik Araştırmalar Dergisi, 2010(1), 27-35.

Kendir, H., Arslan, E. ve Özçelik Bozkurt, H. (2018). Devam Bağlılığı, Presenteeism ve İşten Ayrılma Niyeti Arasındaki İlişki: Beş Yıldızlı Otel İşletmelerinde Bir Araştırma. İşletme Araştırmaları Dergisi, 10(4), 1029-1046.

Kendir, H., Arslan, E. ve Asan, H. (2019). Determination of Winter Trekking Routes Within The Scope Of Winter Tourism Potential in Sivas Province. Journal of Recreation and Tourism Research, 6(3), 294-305.

Morrison, A. M. (1989). Hospitality and Travel Marketing. Delmar Publishers Inc., United States of America

Özgüner, H. 2004. Doğal Peyzajın İnsanların Psikolojik ve Fiziksel Sağlığı Üzerine Etkileri, Süleyman Demirel Üniversitesi Orman Fakültesi Dergisi, 2, 97-107.

Topay, M. ve Küçük, V. (2010). Termal ve Maden Suları Tesislerinde Peyzaj Tasarımının Önemi. Bartın Orman Fakültesi Dergisi, 12(17), 83-91.

Özdemir, G. (2008). Destinasyon Pazarlaması. (1.Baskı) Ankara: Detay Yayınları: 37.

Yeşiltaş, M., Türkmen, F., ve Ayaz, N. (2011). Otel İşletmelerinde Algılanan Örgütsel Prestijin Örgütsel Vatandaşlık Davranışları Üzerindeki Etkileri. CÜ İktisadi ve İdari Bilimler Dergisi, 12(2), 171-189. 